\title{
REVIEW
}

\section{Streptococcus pneumoniae: from molecular biology to host-pathogen interactions*}

\author{
Pedro García, Miriam Moscoso, Violeta Rodríguez-Cerrato, José Yuste, Ernesto García \\ Departamento de Microbiología Molecular y Biología de las Infecciones, Centro de Investigaciones Biológicas \\ (CSIC), and CIBER de Enfermedades Respiratorias (CIBERES), Madrid, Spain
}

Received $23^{\text {rd }}$ February 2010.

Revised $8^{\text {th }}$ April 2010.

Published online $6^{\text {th }}$ May 2010.

\begin{abstract}
Summary
Streptococcus pneumoniae is the main cause of community acquired pneumonia and also produces meningitis, bacteremia, and otitis media, among others. Worldwide, these infections are the cause of substantial morbidity and mortality. Many different virulence factors have been described and most of them are surface-located macromolecules, namely, the capsular polysaccharide and various pneumococcal proteins. Cell wall hydrolases (CWHs) specifically cleave covalent bonds of the peptidoglycan and associated polymers: most CWHs are choline-binding proteins (CBPs) and are among the most well-known surface proteins. Pneumococcal CBPs have been investigated due to their role in pathogenesis and as candidate antigens for improved vaccines. Among the complex host-parasite interactions characteristic of pneumococcal disease, nasopharyngeal colonization is the first step. CBPs appear to play a central role in the development of the carrier state, possibly by affecting biofilm formation and development. Although the role of biofilms in the pathogenesis of some chronic human infections is currently widely accepted, the molecular bases underlying the formation of pneumococcal biofilms are only recently being studied. Among therapeutic strategies to combat multidrug-resistant pneumococcal infections, the use of purified phage- or bacteria-encoded CWHs both in vitro and in animal models is under investigation.
\end{abstract}

Key words: Pneumococcus; cell wall hydrolases; choline; phage therapy; biofilm; enzybiotics

*This review is dedicated to Prof. Rubens López García, our friend and former mentor.

\section{INTRODUCTION}

Streptococcus pneumoniae, a Gram-positive facultative anaerobe, is currently one of the most important human pathogens and a worldwide leading

\footnotetext{
$\triangle \quad$ Ernesto García, Centro de Investigaciones Biológicas, CSIC, Ramiro de Maeztu, 9, 28040 Madrid, Spain

ㅁ.garcia@cib.csic.es

ㅇㅛㅛ $\quad 34918373112$

冝 $\quad 34915360432$
}

cause of bacterial pneumonia, meningitis, and sepsis. The bacterium is carried asymptomatically in the nasopharynx of healthy children and, less frequently, of healthy adults, with colonization beginning shortly after birth. In the industrialized countries, serious pneumococcal disease occurs mainly in children below the age of five, the elderly, and immunocompromised patients. In developing countries, these diseases are common in children under five, including newborn infants; but the rates of the disease in the elderly population are largely unknown. Respiratory infections are responsible for the death of 4 million persons each year, and $S$. pneumoniae is the predominant species in these 
infections. Although in developed countries a substantial reduction in pneumonia mortality during the $20^{\text {th }}$ century has been observed, in the low-income countries of Asia and Africa, pneumonia is still the main cause of child death. In developing countries, over one-quarter of children have an episode of clinical pneumonia each year throughout the first 5 years of their lives (Scott et al. 2008). Recent estimates in children aged 1-59 months reported about 14.5 million episodes of serious pneumococcal disease and deaths ranging from 700,000 to 1 million every year worldwide (O'Brien et al. 2009). Of the 14.5 million pneumococcal cases, $95 \%$ were attributable to pneumonia.

Even though $S$. pneumoniae mutants with increased resistance to penicillin had been isolated in vitro and in vivo from experimental animals in the 1940s, clinical pneumococcal isolates were uniformly susceptible to low concentrations of this antibiotic until the mid-sixties. Two decades were to pass before reports of resistant isolates from humans were described in the United States and Australia. Gradually, the spread of penicillin and multiple-antibiotic resistant pneumococcal strains became worldwide. In the United States, about 44\% of all pneumococcal strains are now resistant to $\beta$-lactam antibiotics; in Spain, about $41 \%$ are resistant. This situation has prompted the development of new anti-infectives for the treatment of pneumococcal infections, particularly those produced by multi-drug resistant pneumococci (Maestro and Sanz 2007).

Growing resistance of $S$. pneumoniae to conventional antibiotics emphasizes the urgent need for new antipneumococcal drugs and vaccines to control pneumococcal disease. The pneumococcal capsular polysaccharide (CPS) is immunogenic and induces type-specific protective immunity (López 2006). Although a 23-valent non-conjugated CPS vaccine for use in adults and children aged $\geq 5$ years and a heptavalent protein-polysaccharide conjugate vaccine (designed for pediatric use) are currently available, they are far from satisfactory. Pronounced herd immunity has resulted in a decrease in invasive pneumococcal diseases in vaccinees and non-vaccinees and reduced antibiotic resistance rates. However, recent studies report that serotypes eradicated by the vaccines are being replaced by non-vaccine pneumococcal serotypes. This so-called 'serotype replacement' might soon threaten the success of vaccine use (Dagan 2009).

Our group has been working during more than 30 years on the molecular biology of $S$. pneumoniae, namely in surface proteins involved in virulence (e.g., cell wall hydrolases; CWHs), CPS biosynthesis and regulation, and its bacteriophages. As most of the results obtained up to 2004 have been reviewed (López and García 2004, López et al. 2004a, López et al. 2004b, García et al. 2005, Hermoso et al. 2007), in the present review we will update our current research efforts aimed at further insight into the structure-function relationships of pneumococcal CWHs and their role in virulence. Furthermore, the state-of-the-art of biofilm development and regulation as well as the therapeutic value of bacterium- and phage-encoded CWHs will be discussed in the framework of host-S. pneumoniae interplay.

\section{CHOLINE AND CELL WALL HYDROLASES}

S. pneumoniae has a unique physiological trait among prokaryotes: it exhibits an absolute nutritional requirement for choline. This aminoalcohol incorporates as phosphorylcholine (PC) in the cell wall teichoic acid (TA) and membrane lipoteichoic acid. Depending on the particular strain, each repeat unit of TA contains one or two PC residues. We have studied some aspects of this auxotrophy and confirmed the key role of TacF protein (a TA repeat unit transporter) in the choline-dependent phenotype. Besides this, we have also demonstrated that at least two tacF mutations are required to confer an improved fitness to the choline-independent pneumococcal strains when growing in medium lacking any aminoalcohol (González et al. 2008).

S. pneumoniae contains several CWHs, enzymes that degrade specific linkages of the cell wall. PC acts as an anchor for a special class of surface-located proteins, referred to as choline-binding proteins (CBPs), through non-covalent interactions. Most pneumococcal CWHs are CBPs and harbor two functional modules: one is responsible of the substrate binding and the other determines the site of action. $S$. pneumoniae produces 13 to 16 CBPs depending on the particular strain. The choline-binding module $(\mathrm{CBM})$ is formed by several repeats (choline-binding repeats; CBRs), with the consensus motif GWXK-X ${ }_{4-5}-W Y Y-\varphi-X_{3-5}-G_{X M X}$, where $X$ is any residue and $\varphi$ is a hydrophobic residue (http://pfam.sanger.ac.uk/family?PF01473). The relevant characteristics of the pneumococcal CBPs mentioned in this review are summarized in Table 1. The first crystal structure of a CBM showed that the $\mathrm{COOH}-(\mathrm{C}-)$ terminal module of the LytA major pneumococcal autolysin, an $N$-acetylmuramoylL-alanine amidase (NAM-amidase), adopts a peculiar $\beta$-solenoid structure (Fernández-Tornero et al. 2001). Each CBR comprises a $\beta$-hairpin followed 
García et al.: Streptococcus pneumoniae: from molecular biology to host-pathogen interactions

Table 1. Characteristics of selected pneumococcal and phage cell wall hydrolases.

\begin{tabular}{|c|c|c|c|c|c|c|}
\hline Protein & Gene & $\begin{array}{l}\text { Signal } \\
\text { peptide }\end{array}$ & $\begin{array}{l}\text { Number of } \\
\text { amino acid } \\
\text { residues }^{\mathrm{a}}\end{array}$ & $\begin{array}{l}\text { Molecular } \\
\text { mass }(\mathrm{kDa})^{\mathrm{b}}\end{array}$ & $\begin{array}{l}\text { Catalytic } \\
\text { activity }\end{array}$ & $\begin{array}{l}\text { Number } \\
\text { of CBRs }\end{array}$ \\
\hline \multicolumn{7}{|c|}{ S. pneumoniae ${ }^{\mathrm{d}}$} \\
\hline LytA & spr1754 & No & 318 & 36.6 & NAM-amidase & $7(\mathrm{C})$ \\
\hline LytB & spr0867 & Yes & $679(702)$ & $79.3(81.9)$ & $\begin{array}{l}\text { endo- } \beta-N \text { - } \\
\text { acetylglucosaminidase }\end{array}$ & $18(\mathrm{~N})$ \\
\hline LytC & spr1431 & Yes & $468(490)$ & $55.2(57.4)$ & Lysozyme & $11(\mathrm{~N})$ \\
\hline $\begin{array}{c}\text { Pce } \\
(\mathrm{CbpE})\end{array}$ & spr0831 & Yes & $602(627)$ & $69.4(72.1)$ & $\begin{array}{l}\text { Phosphorylcholine } \\
\text { esterase }\end{array}$ & $10(\mathrm{C})$ \\
\hline $\begin{array}{r}\mathrm{CbpF} \\
(\mathrm{CbpC})\end{array}$ & spr0337 & Yes & $311(338)$ & $36.3(39.3)$ & $\mathrm{ND}^{\mathrm{e}}$ & $5(\mathrm{C})$ \\
\hline CbpD & spr2006 & Yes & $408(448)$ & $46.0(50.4)$ & Peptidase, putative & $4(\mathrm{C})$ \\
\hline Spr1274 & spr1274 & No & 129 & 14.6 & $\mathrm{ND}^{\mathrm{e}}$ & $4(\mathrm{C})$ \\
\hline \multicolumn{7}{|l|}{ Phage Cp-1 } \\
\hline Cpl-1 & cpll & No & 339 & 39.2 & Lysozyme & $6(\mathrm{C})$ \\
\hline \multicolumn{7}{|c|}{ Phage Dp-1 } \\
\hline Pal & pal & No & 296 & 34.4 & NAM-amidase & $7(\mathrm{C})$ \\
\hline
\end{tabular}

${ }^{a}$ The number of residues of the unprocessed protein is indicated in parentheses.

${ }^{b}$ The molecular mass of the unprocessed protein is indicated in parentheses.

${ }^{c}$ The numbers correspond to consensus and non-consensus choline-binding repeats (CBRs). N and C indicate, respectively, whether the CBRs are located at the $\mathrm{N}-$ or $\mathrm{C}-$ terminal region of the protein.

${ }^{\mathrm{d}}$ The data correspond to the genome of the common laboratory strain R6. Alternative protein designations are shown in parentheses.

${ }^{\mathrm{e}} \mathrm{ND}$, not determined.

by a loop and a coiled region (Fig. 1a). Choline-binding sites, as described for other CBPs, are located at the interface of two consecutive CBRs, where three structurally conserved aromatic residues form a cavity in which the choline quaternary ammonium moiety is stabilized primarily by cation- $\pi$ interactions.

The crystal structure elucidation of CBPs is a crucial step to gain insight in the structural and functional knowledge of these proteins. Fig. 1 shows the crystal structures of host and phage-encoded CBPs that have been solved to date. Relevant aspects of the four CBPs most recently crystallized are the following: a) Pce, a phosphorylcholinesterase, removes a limited number of PC residues from the cell wall TAs. Also, Pce is able to hydrolyze the platelet-activating factor (PAF; 1-alkyl-2-acetoyl-hexadecyl-glycero-3phosphoryl choline), which suggests that this enzyme has other functions during infection, such as degrading host PC-containing compounds. The cell surface localization of Pce could facilitate the hydrolysis of PAF from the bloodstream and might play a role in the mechanism of pneumococcal adherence and invasiveness (see below). Pce has a globular $\mathrm{NH}_{2}-(\mathrm{N}-)$ terminal module containing a binuclear $\mathrm{Zn}^{2+}$ catalytic center, and an elongated CBM joined by a short linker of 12 amino acids (Fig. 1c). 
This structure has revealed that the removal of PC residues is limited by the configuration of the active site and, thus, only residues located at the end of the TA chains are accessible to the catalytic center (Hermoso et al. 2005).

b) $\mathrm{CbpF}$ is not a $\mathrm{CWH}$ but presents unique features compared with other CBPs, as it is assembled entirely by CBRs composed both of consensus and non-consensus repeats distributed along its length, which markedly alter its shape, charge distribution and binding ability, and organizing the protein into two well-defined modules (Fig. 1e). Sequence divergence observed in $\mathrm{CbpF}$ is generated by mutations of the consensus amino acid residues of the repeat, by amino acid additions in the $\beta$-hairpin turn or the loop, or by a combination of both. Biochemical studies have shown that CbpF selectively modulates the autolytic function of the LytC lysozyme and the divergent $\mathrm{CBRs}$ that build its $\mathrm{N}$-terminal module have a crucial role in this effect. It is worth noting that analyses of known pneumococcal genomes show the existence of several proteins that are likely to display the same architecture as $\mathrm{CbpF}$, which might constitute a new subfamily within the CBPs (Molina et al. 2009).

c) The structure of the autolysin LytC presents an unusual hook-shaped conformation with a catalytic module resembling a flattened ellipsoid folding into an irregular $(\beta / \alpha)_{5} \beta_{3}$ barrel, and eleven CBRs in the substrate recognition module (Fig. 1f). Structural and biochemical data allow an explanation of the coordinated role of LytC and CbpD (another CBP with CWH activity) in fratricide, a competence-programmed mechanism of predation of noncompetent sister cells (Claverys and Håvarstein 2007). LytC is only able to hydrolyze non-crosslinked peptidoglycan chains, a property probably connected to a new type of choline-binding site with a characteristic GYMA motif at the end of the third repeat. Docking experiments have indicated that the presence of these GYMA sites on the CBM could enhance the affinity for the $\mathrm{PC}$ and $N$-acetylgalactosamine sugars of the TAs by providing a strong multivalent recognition and attachment to the cell wall. The configuration around the active site imposed limitations on hydrolysis of peptidoglycan, which means that only when specific cuts are introduced in the peptide stems of peptidoglycan in the target cells, do glycan chains become fully predisposed to the LytC activity. Therefore, prior cleavage of the peptide stems performed by CbpD should facilitate hydrolysis of the non-crosslinked peptidoglycan chains by LytC (Pérez-Dorado et al. 2010).

d) Spr1274 is a putative CBP of unknown function (Fig. 1d). The crystal structure of its CBM (residues 44-129) has been solved with three molecules in the asymmetric unit, forming a pseudo-trimer. Chains $\mathrm{A}$ and $\mathrm{C}$ are antiparallel and interact with the two termini of chain B. No common threefold axis can be found in the pseudo-trimer, but two fold axes are present between chains $\mathrm{A}$ and $\mathrm{B}$ and between chains $\mathrm{A}$ and $\mathrm{C}$. The overall shape is like the letter $\mathrm{V}$, with an angle of $\sim 60^{\circ}$ between the two superhelices (Zhang et al. 2009).

Taking advantage of the specific binding of the aminoalcohol choline and its analogs to the CBPs, we have tested a highly promising new approach for the development of drugs to treat pneumococcal infections. It is is based on dendrimers (tree-like branched molecules) used as a scaffold for the attachment of choline groups to the tip of the branches. Thus, the choline ends can simultaneously occupy multiple choline-binding sites of the CBPs. Exogenously choline-charged dendrimers competitively inhibit the binding of CBPs to the cell wall, blocking cell separation and the characteristic autolysis at the end of the stationary phase of growth, inducing instead the formation of long chains or even preventing growth. These effects were observed at low micromolar concentrations of the higher-generation dendrimers, which represents a $10^{3}-10^{4}$-fold increase of apparent affinity compared to monovalent choline (Hernández-Rocamora et al. 2009). A further development of this dendrimer approach is currently under study using several choline analogs that display a higher binding affinity to CBPs than choline. In fact, inhibition of pneumococcal CBPs and cell growth by esters of bicyclic amines has already been demonstrated (Maestro et al. 2007).

The CBM of LytA is essential to guarantee full enzymatic activity through dimerization. In this sense, analysis of a collection of 21 mutated LytA NAM-amidases indicated that Ile-315, located in the last CBR, is a key amino acid residue in both enzymatic activity and folding (Romero et al. 2007). Moreover, it is worth to mention that selective interaction of the CBM of LytA with choline or its analogs (tertiary or quaternary amines) has allowed its use as a tag to construct a variety of fusion proteins that may be purified using DEAE-cellulose, which acts as an affinity matrix for CBM-containing proteins (Sánchez-Puelles et al. 1992, Moldes et al. 2004). In this sense, a commercial kit based in this system is already available (C-LYTAG; http://www.biomedal.com). In addition to amine-containing solid supports, aqueous two-phase solutions containing polyethylene glycol have also been used for purification of proteins tagged with CBMs (Maestro et al. 2008). 

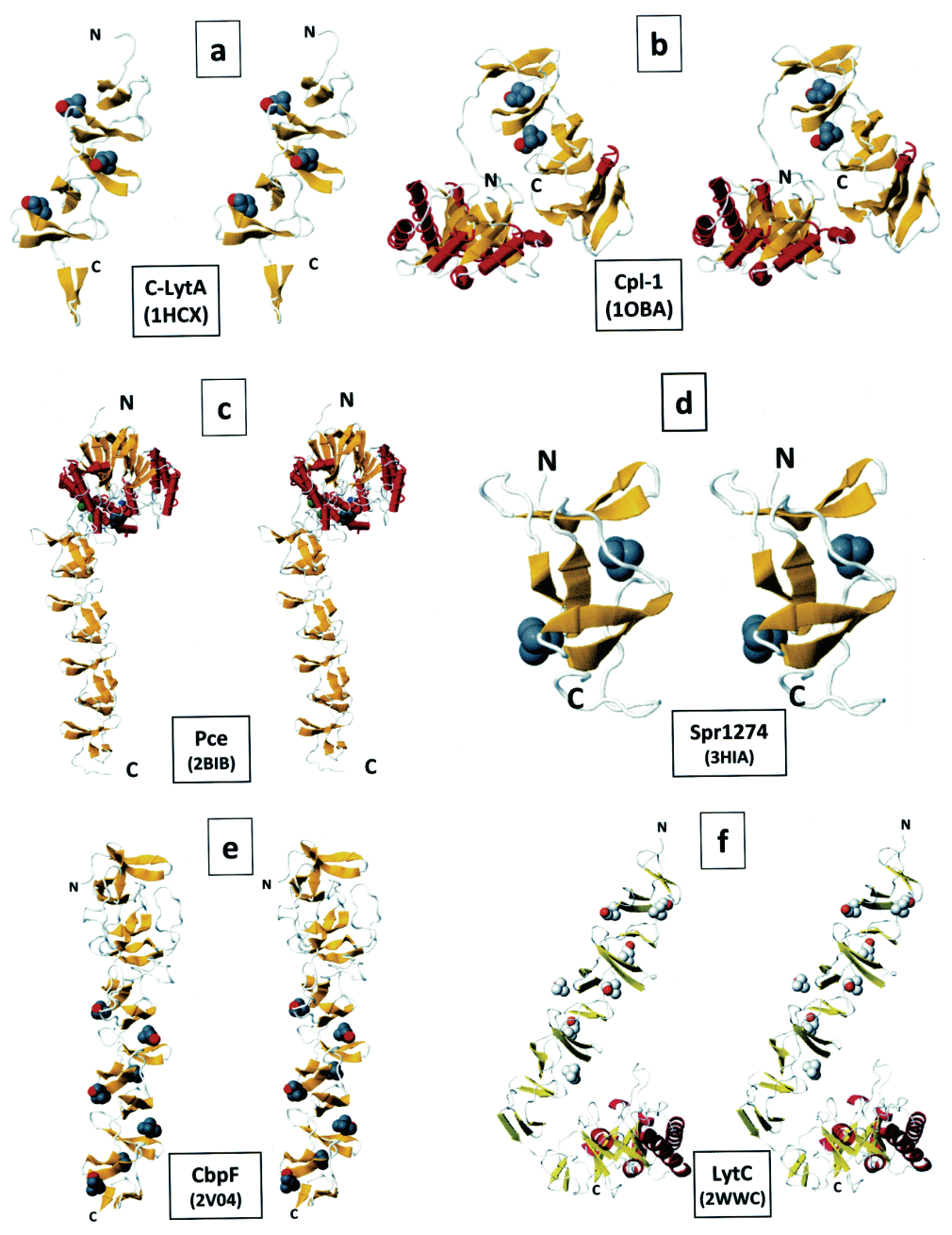

Fig. 1. Three-dimensional structures of several choline-binding proteins of $\boldsymbol{S}$. pneumoniae. The stereo diagrams were visualized with FISTGLANCE in JMOL (http://molvis.sdsc.edu/fgij/index.htm) or PyMOL (http://www.pymol.org/). For C-lytA and Spr1274 only one monomer is shown for clarity. Rockets (or helices in panel f) and planks represent, respectively, $\alpha$-helices and $\beta$-strands. $\mathrm{N}$ and $\mathrm{C}$ indicate the $\mathrm{NH}_{2}-$ and the $\mathrm{COOH}$ - termini of the protein, respectively. PC molecules are depicted in $\mathrm{CPK}$ mode. The PDB identification numbers are indicated in parentheses.

\section{PNEUMOCOCCAL BIOFILMS}

A biofilm is a sessile microbial community where structured populations of microorganisms are adhered to a surface or interface and embedded in an extracellular matrix of polymeric substances. The importance of biofilms in medical microbiology lies in that more than $60 \%$ of human infections are related to growth in biofilms and to the inherent tolerance of these communities to antimicrobials and host immune defense system. Biofilms have been associated with several chronic infections (up to $80 \%$ of these) including chronic otitis media. Formation of pneumococcal biofilms on the mucosal epithelial cells from children with recurrent or chronic middle ear infections has been recently observed (Hoa et al. 2009). However, until five years ago no information on pneumococcal biofilms at the structural or genetic level was reported. Our research group has developed the set-up of a suitable biofilm model for S. pneumoniae in microtiter plates or glass-bottom dishes to analyze the influence of several environmental factors and to study its peculiar structure (Moscoso et al. 2006, 2009).

Environmental changes analogous to those found in the nasopharynx, such as nutrient content of the 
medium, $\mathrm{pH}$, and osmolarity, influence biofilm formation in vitro. Nonencapsulated pneumococcal strains generate a three-dimensional structure where the adherent cells formed a mat of cells about 25 to $30 \mu \mathrm{m}$ deep, as revealed by confocal laser scanning microscopy (Moscoso et al. 2006). Also, using low-temperature scanning electron microscopy, it was found that pneumococcal cells growing in biofilms are interconnected by small, thin filaments and adopted regular shapes to form honeycomb-like structures (Fig. 2).

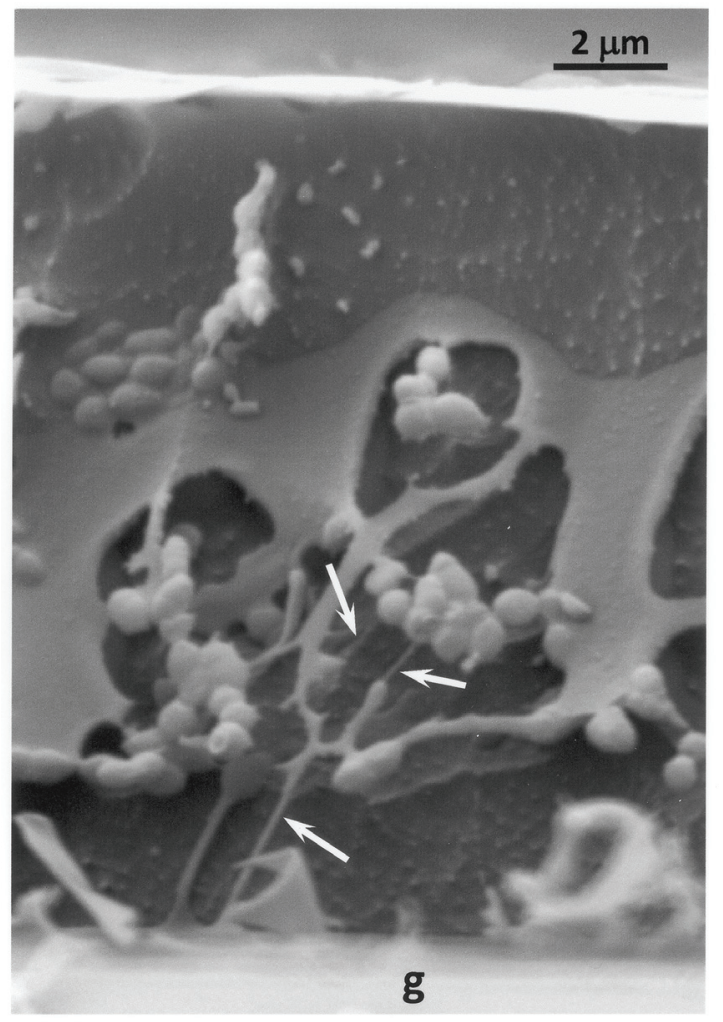

Fig. 2. Low-temperature scanning electron micrograph of a pneumococcal biofilm formed on the surface of a glass coverslip (g). Arrows indicate filamentous material linking pneumococci to each other and to the intercellular matrix.

Extracellular DNA as well as extracytoplasmic and/or surface-exposed proteins appear to be important components of the biofilm matrix and are required for pneumococcal biofilm formation and maintenance (Moscoso et al. 2006). Extracellular polysaccharides often determine the biofilm architecture and provide the structural integrity for the three-dimensional biofilm matrix. CPS, which is absolutely required for pneumococcal virulence, represents a partial physical barrier in the first steps of biofilm formation since only reduced biofilm formation was found when encapsulated, clinical isolates or isogenic transformants were tested (Moscoso et al. 2006). However, a minimum amount of CPS is absolutely required for efficient nasopharyngeal colonization in mice, although it plays an essential protective role against phagocytosis during invasive infection. It has been shown that biofilm development may select nonencapsulated phenotypic variants (Domenech et al. 2009). Several different mutations were found among the type 3 capsular mutants that appeared in biofilms formed on polystyrene plates. Most strains contained single nucleotide polymorphisms in cap3A, the first gene of the type 3 capsular operon (Moscoso and García 2009) and encoding a UDP-glucose dehydrogenase; one had a mutated -10 promoter hexamer (CATAAT), and three had large deletions affecting cap $3 A$ and, in one case, also cap $3 B$. We have proposed that non-encapsulated mutants of pneumococcal type 3 strains are essentially involved in the initial stages (the attachment stage) of biofilm formation during colonization/pathogenesis (Domenech et al. 2009).

The fact that pneumococcal biofilm is CPS-independent indicates that one or more extracellular polysaccharides other than CPS, are involved in structuring of the biofilm matrix. Staining of pneumococcal biofilms with various lectins has provided evidence of the presence of an extracellular polysaccharide (unpublished data).

Several genes have been reported to be important for biofilm formation of pneumococci. Gene expression profiles of pneumococci recovered from the lungs and brains of infected mice have been reported to be similar to those of pneumococci grown in biofilms in vitro. Proteomic analysis confirmed that the biofilm development process exhibited by $S$. pneumoniae is correlated not only with differential production of proteins but also with a dramatic increase in the number of detectable proteins involved in adhesion, resistance and virulence (Allegrucci et al. 2006). Mutations in genes encoding CBPs have been shown to decrease the capacity of pneumococci to form biofilms. Thus, CBPs such as the CWHs (e.g., the NAM-amidase LytA, the LytC lysozyme, or the LytB glucosaminidase), the pneumococcal surface protein $\mathrm{A}$ and the CbpA adhesin, were shown to contribute to $S$. pneumoniae biofilm formation (Moscoso et al. 2006). More recently, a large number of transposon insertion strains were generated as an approach to the identification of genes involved in pneumococcal biofilm formation (Muñoz-Elías et al. 2008). Such collection of mutants included strains 
with genes encoding CBPs, adhesins, extracellular proteases, efflux pumps, transporters, and transcriptional regulators.

\section{HOST-PATHOGEN INTERACTIONS}

Pneumococcal disease is preceded by the colonization of the nasopharynx, which is particularly common in children (see above) and involves binding of the bacterium to cell-surface carbohydrates. This process is mediated by cell-wall-associated surface proteins (Bogaert et al. 2004). Using CWH-deficient strains and a human nasopharyngeal cell line we have found that LytB and LytC play a key role in the colonization of the upper respiratory tract and the establishment of nasopharyngeal carriage. LytB or LytC deficient strains displayed a reduced ability to colonize the nasopharynx of infected mice when compared to the wild-type strain. Our studies have demonstrated that these CWHs are important surface-exposed proteins involved in the adhesion and colonization of the mucosal surfaces of the nasopharynx.

The transition from the carrier state to invasion involves genotypic and phenotypic changes, many of which lead to enhanced bacterial adherence to host cells. Activation of endothelial or epithelial cells results in up-regulation of the PAF receptor (PAFr) at their surface, which in turn, promotes the recognition of PAFr by PC, thus facilitating invasion by S. pneumoniae throughout this receptor (Cundell et al. 1995). Choline is a key component of the bacterial envelope of S. pneumoniae (see above) and it is involved in the adhesion to nasopharyngeal epithelial cells and the establishment of pneumococcal disease (Kharat and Tomasz 2006). The hydrolysis of PC and PAF by the Pce enzyme suggests that $S$. pneumoniae has developed complex virulence mechanisms that are involved in the processing of PC and host cell adhesion as previously proposed (Hermoso et al. 2005). To establish the infection, a microorganism must first overcome the host's innate immunity and, in the case of pneumococcal infection, a key bacterial element recognized by the innate immune system is the cell wall. Cell wall fragments released in vivo during bacterial autolysis mediated by pneumococcal CWHs, contribute to inflammation and cell damage (López and García 2004). Some of these components interact with membrane-bound Toll like receptors (TLRs), particularly TLR2, and induce a proinflammatory response. Furthermore, it is proposed that peptidoglycan degradation products interact with Nod proteins that are intracellular surveillance proteins that recognize subcomponents of peptidoglycan (van der Poll and Opal 2008). Therefore, CWHs might be involved in triggering some of these physiological events.

Descriptions of virulence characteristics of S. pneumoniae generally focus on its ability to escape unharmed from the immune system and breach host barriers leading to a widespread invasion. Acute phase proteins such as the $\mathrm{C}$-reactive protein (CRP) or the serum amyloid $\mathrm{P}$ component (SAP) recognize $\mathrm{PC}$ on the bacterial surface and activate complement-mediated immunity, which is one of the first defence lines against invading pathogens such as S. pneumoniae, controlling bacterial replication in the lungs and in the systemic circulation (Yuste et al. 2007). Limiting the content of PC by Pce might impair the activation of the classical pathway mediated by CRP or SAP, and therefore, Pce could play an important role in pneumococcal pathogenesis.

To avoid complement immunity and phagocytosis, S. pneumoniae has developed a wide arsenal of bacterial virulence factors. Among them, PspA and pneumolysin, which is released to the medium after cell wall lysis mediated by LytA, contribute synergistically to the innate immune diversion by targeting complement immunity at different levels. All these factors increase the ability of S. pneumoniae to cause invasive disease (Yuste et al. 2005).

\section{ENZYBIOTICS AND PHAGE THERAPY}

The emergence and steady spread of antibiotic-resistant $S$. pneumoniae infections have determined the investigation of alternative treatment strategies. A novel therapeutic approach is based on the administration of purified recombinant $\mathrm{CWHs}$ encoded either by bacteriophages (López et al. 2004a, Hermoso et al. 2007, Romero et al. 2009 a, b) or by the bacterium itself (Rodríguez-Cerrato et al. 2007b) to specifically kill bacterial species in which enzyme-mediated lysis naturally occurs.

Bacteriophages have been used for years in the prevention and/or treatment of bacterial infections in some parts of the world (for a recent review, see O'Flaherty et al. 2009). Several in vivo and in vitro studies have showed the efficacy of phage therapy as an alternative (or complement) to conventional antibiotic therapy. Most bacteriophages encode a lytic system containing a holin that causes membrane damage, and at least one $\mathrm{CWH}$ (endolysin) that destroy the bacterial cell wall and thus allow the phage to disseminate its progeny.

Recently, the use of purified phage-encoded endolysins as enzybiotics to control pathogenic 
bacteria has been tested. Two purified pneumophage lytic enzymes, the lysozyme $\mathrm{Cpl}-1$ and the NAM-amidase Pal, have been used with promising efficacy in a murine sepsis model of pneumococcal infection. This study demonstrated that $\mathrm{Cpl}-1$, alone or combined with Pal, afforded protection from pneumococcal bacteremia and death (López et al. 2004a). Therapy with Cpl-1 has also been tested in other experimental models of $S$. pneumoniae infections, including endocarditis, meningitis and pneumonia, with promising results (O'Flaherty et al. 2009, Witzenrath et al. 2009). Although not tested yet in vivo, a remarkable phage endolysin is the CHAP domain-containing NAM-amidase Skl that is encoded by a prophage from Streptococcus mitis SK137 strain (Llull et al. 2006).

In an innovative approach in the field of enzybiotic therapy, we have recently demonstrated the antipneumococcal efficacy of recombinant LytA and compared such effect with that of phage lysins both in vitro and in a murine sepsis model (Rodríguez-Cerrato et al. 2007a, b). The rationale for the exogenous administration of purified LytA as antibacterial agent was based on the role of LytA in pneumococcal physiology, i.e., LytA causes bacterial cell lysis during the late stationary phase of growth by specifically breaking the amidase bonds between the glycan strands and the peptide moieties of the peptidoglycan.

Two serotype 3, penicillin-susceptible strains and two penicillin- and cefotaxime-resistant (serotypes 19F and 19A, respectively) S. pneumoniae clinical isolates were exposed to several combinations of Cpl-1, Pal, and/or LytA, and antibiotics (cefotaxime and moxifloxacin) using chequerboard and time-kill assays (Rodríguez-Cerrato et al. 2007a). By the chequerboard technique, although synergy between LytA and Pal was not found for the four strains, the combination of LytA and cefotaxime was synergistic for one of the two cefotaxime-resistant strains studied. The combined use of Cpl-1 and Pal was synergistic for three of the four strains, as was Cpl-1 with antibiotics for two of the three strains studied.

In our study of mice infected with a multidrug-resistant, meningeal pneumococcal strain, intraperitoneal or intravenous therapy with purified LytA and intraperitoneal therapy with high-dose Cpl-1 achieved significant declines in bacterial counts (ca. 3-5 $\log _{10}$ colony-forming units $\mathrm{ml}^{-1}$ ) in peritoneum and blood, compared to those of non-treated animals (Rodríguez-Cerrato et al. 2007b). Further research using these and new lytic enzymes as potential antipneumococcal agents is ongoing in our laboratory.

\section{ACKNOWLEDGMENTS}

We are indebted to J. A. Hermoso for his help in the preparation of Fig. 1. This review was prepared within the outlined actions of the Projects SAF2006-00390 and SAF2009-10824. CIBER de Enfermedades Respiratorias (CIBERES) is an initiative of ISCIII. VR-C is supported by the Subprograma Juan de la Cierva (JCI-2008-02690; Ministerio de Ciencia e Innovación).

\section{REFERENCES}

Allegrucci M, Hu FZ, Shen K, Hayes J, Ehrlich GD, Post JC, Sauer K: Phenotypic characterization of Streptococcus pneumoniae biofilm development. J Bacteriol 188:2325-2335, 2006.

Bogaert D, de Groot R, Hermans PWM: Streptococcus pneumoniae colonisation: the key to pneumococcal disease. Lancet Infect Dis 4:144-154, 2004.

Claverys J-P, Håvarstein LS: Cannibalism and fratricide: mechanisms and raisons d'être. Nat Rev Microbiol 5:219-229, 2007.

Cundell DR, Gerard NP, Gerard C, Idänpään-Heikkilä I, Tuomanen EI: Streptococcus pneumoniae anchor to activated human cells by the receptor for platelet-activating factor. Nature 377:435-438, 1995.

Dagan R: Serotype replacement in perspective. Vaccine 27:C22-C24, 2009.

Domenech M, García E, Moscoso M: Versatility of the capsular genes during biofilm formation by Streptococcus pneumoniae. Environ Microbiol 11:2542-2555, 2009.

Fernández-Tornero C, López R, García E, Giménez-Gallego G, Romero A: A novel solenoid fold in the cell wall anchoring domain of the pneumococcal virulence factor LytA. Nat Struct Biol 8:1020-1024, 2001.

García P, García JL, López R, García E: Pneumococcal phages. In Waldor MK, Friedman DLI, Adhya S (ed.): Phages: Their Role in Bacterial Pathogenesis and Biotechnology, ASM Press, Washington, D.C. 2005, pp. 335-361.

González A, Llull D, Morales M, García P, García E: Mutations in the $t a c F$ gene of clinical strains and laboratory transformants of Streptococcus pneumoniae: impact on choline auxotrophy and growth rate. J Bacteriol 190:4129-4138, 2008.

Hermoso JA, Lagartera L, González A, Stelter M, García P, Martínez-Ripoll M, García JL, Menéndez M: Insights into pneumococcal 
pathogenesis from the crystal structure of the modular teichoic acid phosphorylcholine esterase Pce. Nat Struct Mol Biol 12:533-538, 2005.

Hermoso JA, García JL, García P: Taking aim on bacterial pathogens: from phage therapy to enzybiotics. Curr Opin Microbiol 10:461-472, 2007.

Hernández-Rocamora VM, Maestro B, de Waal B, Morales M, García P, Meijer EW, Merkx M, Sanz JM: Multivalent choline dendrimers as potent inhibitors of pneumococcal cell-wall hydrolysis. Angew Chem Int Ed Engl 48:948-951, 2009.

Hoa M, Tomovic S, Nistico L, Hall-Stoodley L, Stoodley P, Sachdeva L, Berk R, Coticchia JM: Identification of adenoid biofilms with middle ear pathogens in otitis-prone children utilizing SEM and FISH. Int $\mathrm{J}$ Pediatr Otorhinolaryngol 73:1242-1248, 2009.

Kharat AS, Tomasz A: Drastic reduction in the virulence of Streptococcus pneumoniae expressing type 2 capsular polysaccharide but lacking choline residues in the cell wall. Mol Microbiol 60:93-107, 2006.

Llull D, López R, García E: Skl, a novel choline-binding $N$-acteylmuramoyl-L-alanine amidase of Streptococcus mitis SK137 containing a CHAP domain. FEBS Lett 580:1959-1964, 2006.

López R: Pneumococcus: the sugar-coated bacteria. Int Microbiol 9:179-190, 2006.

López R, García E: Recent trends on the molecular biology of pneumococcal capsules, lytic enzymes, and bacteriophage. FEMS Microbiol Rev 28:553-580, 2004.

López R, García E, García P: Enzymes for anti-infective therapy: phage lysins. Drug Discov Today Ther Strateg 1:469-474, 2004a.

López R, García E, García P, García JL: Cell wall hydrolases. In Tuomanen EI, Mitchell TJ, Morrison DA, Spratt BG (eds.): The Pneumococcus, ASM Press, Washington, D.C. 2004b, pp. 75-88.

Maestro B, Sanz JM: Novel approaches to fight Streptococcus pneumoniae. Recent Pat Antiinfect Drug Discov 2:188-196, 2007.

Maestro B, González A, García P, Sanz JM: Inhibition of pneumococcal choline-binding proteins and cell growth by esters of bicyclic amines. FEBS J 274:364-376, 2007.

Maestro B, Velasco I, Castillejo I, Arévalo-Rodríguez M, Cebolla A, Sanz JM: Affinity partitioning of proteins tagged with choline-binding modules in aqueous two-phase systems. J Chromatogr A 1208:189-196, 2008.
Moldes C, García JL, García P: Construction of a chimeric thermostable pyrophosphatase to facilitate its purification and immobilization by using the choline-binding tag. Appl Environ Microbiol 70:4642-4647, 2004.

Molina R, González A, Stelter M, Pérez-Dorado I, Kahn R, Morales M, Moscoso M, Campuzano S, Campillo NE, Mobashery S, García JL, García P, Hermoso JA: Crystal structure of $\mathrm{CbpF}$, a bifunctional choline-binding protein and autolysis regulator from Streptococcus pneumoniae. EMBO Rep 10:246-251, 2009.

Moscoso M, García E: Transcriptional regulation of the capsular polysaccharide biosynthesis locus of Streptococcus pneumoniae: a bioinformatic analysis. DNA Res 16:177-186, 2009.

Moscoso M, García E, López R: Biofilm formation by Streptococcus pneumoniae: role of choline, extracellular DNA, and capsular polysaccharide in microbial accretion. J Bacteriol 188:7785-7795, 2006.

Moscoso M, García E, López R: Pneumococcal biofilms. Int Microbiol 12:77-85, 2009.

Muñoz-Elías EJ, Marcano J, Camilli A: Isolation of Streptococcus pneumoniae biofilm mutants and their characterization during nasopharyngeal colonization. Infect Immun 76:5049-5061, 2008.

O'Brien KL, Wolfson LJ, Watt JP, Henkle E, Deloria-Knoll M, McCall N, Lee E, Mulholland $\mathrm{K}$, Levine OS, Cherian $\mathrm{T}$, for the Hib and Pneumococcal Global Burden of Disease Study Team: Burden of disease caused by Streptococcus pneumoniae in children younger than 5 years: global estimates. Lancet 374:893-902, 2009.

O'Flaherty S, Ross RP, Coffey A: Bacteriophage and their lysins for elimination of infectious bacteria. FEMS Microbiol Rev 33:801-819, 2009.

Pérez-Dorado I, González A, Morales M, Sanles R, Striker W, Vollmer W, Mobashery S, García JL, Martínez-Ripoll M, García P, Hermoso JA: Insights into pneumococcal fratricide from crystal structure of the modular killing factor LytC. Nat Struct Mol Biol 17:576-581, 2010.

Rodríguez-Cerrato V, García P, del Prado G, García E, Gracia M, Huelves L, Ponte C, López R, Soriano F: In vitro interactions of LytA, the major pneumococcal autolysin, with two bacteriophage lytic enzymes (Cpl-1 and Pal), cefotaxime and moxifloxacin against antibiotic-susceptible and resistant Streptococcus pneumoniae strains. J Antimicrob Chemother 60:1159-1162, 2007a.

Rodríguez-Cerrato V, García P, Huelves L, García E, del Prado G, Gracia M, Ponte C, López R, Soriano F: Pneumococcal LytA autolysin, a potent therapeutic agent in experimental peritonitis- 
sepsis caused by highly $\beta$-lactam-resistant Streptococcus pneumoniae. Antimicrob Agents Chemother 51:3371-3373, 2007b.

Romero P, López R, García E: Key role of amino acid residues in the dimerization and catalytic activation of the autolysin LytA, an important virulence factor in Streptococcus pneumoniae. J Biol Chem 282:17729-17737, 2007.

Romero P, García E, Mitchell TJ: Development of a prophage typing system and analysis of prophage carriage in Streptococcus pneumoniae. Appl Environ Microbiol 75:1643-1649, 2009a.

Romero P, Croucher NJ, Hiller L, Hu FZ, Ehrlich GD, Bentley SD, García E, Mitchell TJ: Comparative genomic analysis of 10 Streptococcus pneumoniae temperate bacteriophages. J Bacteriol 191:4854-4862, 2009b.

Sánchez-Puelles JM, Sanz JM, García JL, García E: Immobilization and single-step purification of fusion proteins using DEAE-cellulose. Eur $\mathrm{J}$ Biochem 203:153-159, 1992.

Scott JAG, Brooks WA, Peiris JSM, Holtzman D, Mulhollan EK: Pneumonia research to reduce childhood mortality in the developing world. J Clin Invest 118:1291-1300, 2008. van der Poll T, Opal SM: Host-pathogen interactions in sepsis. Lancet Infect Dis 8:32-43, 2008.

Witzenrath M, Schmeck B, Doehn JM, Tschernig T, Zahlten J, Loeffler JM, Zemlin M, Müller H, Gutbier B, Schütte H, Hippenstiel S, Fischetti VA, Suttorp N, Rosseau S: Systemic use of the endolysin Cpl-1 rescues mice with fatal pneumococcal pneumonia. Crit Care Med 37:642-649, 2009.

Yuste J, Botto M, Paton JC, Holden DW, Brown JS: Additive inhibition of complement deposition by pneumolysin and PspA facilitates Streptococcus pneumoniae septicemia. J Immunol 175:1813-1819, 2005.

Yuste J, Botto M, Bottoms SE, Brown JS: Serum amyloid P aids complement-mediated immunity to Streptococcus pneumoniae. PLoS Pathog 3:e120, 2007.

Zhang Z, Li W, Frolet C, Bao R, di Guilmi A-M, Vernet $T$, Chen Y: Structure of the choline-binding domain of Spr1274 in Streptococcus pneumoniae. Acta Crystallogr Section F Struct Biol Crystall Commun 65:757-761, 2009. 